\title{
Commentary: Thoracic endovascular aortic repair for ruptured pseudocoarctation: "There is no need to like the coming world to see it coming." F.-R. Chateaubriand
}

\author{
Jean Bachet, MD, FEBCTS
}

$\overline{\text { From ADETEC }}$, Suresnes, France.

Disclosures: Author has nothing to disclose with regard to commercial support.

Received for publication Oct 4, 2018; accepted for publication Oct 4, 2018; available ahead of print Nov 13, 2018.

Address for reprints: Jean Bachet, MD, FEBCTS, ADETEC, 1, place Marcel Legras, 92400 Suresnes, France

(E-mail: jean.bachet@yahoo.fr).

J Thorac Cardiovasc Surg 2019;157:e105-6

$0022-5223 / \$ 36.00$

Copyright (c) 2018 by The American Association for Thoracic Surgery

https://doi.org/10.1016/j.jtcvs.2018.10.010

In the short article published in the current issue of The Journal of Thoracic and Cardiovascular Surgery, ${ }^{1}$ Arakawa and coworkers report on a rare and perfectly managed case of rupture of a nondilated aortic pseudocoarctation. The proper diagnosis was promptly made, the adequate interventional intraluminal treatment was immediately carried out, the hemorrhage stopped, and 1 week later the mediastinal and pleural effusion had disappeared and the patient discharged in a few days.

This illustrates, obviously, the quality and the efficacy of the management of this case. Moreover, it outlines dramatically the evolution of the care and treatment of such or similar lesions in the past 2 decades. When, in 1994, Dake and Miller ${ }^{2}$ published the first case of thoracic endovascular aortic repair, the cardiologic and surgical communities were quite interested. Some groups entered the fray and started their own experience.

Nevertheless the method was not adopted rapidly on a large scale. It took years to show that, in emergent conditions, such as dissections or ruptures, and as far as the descending aorta was concerned, the technique was largely superior to the conventional open surgical repair.

However, for the chronic lesions and conditions, reluctance was (and still is) largely present. The occurrence of immediate complications of the method, such as acute rupture, retrograde dissection, endo leaks, increased rates of spinal cord injuries, and so on, constituted strong arguments against the systematic use of thoracic endovascular aortic repair. So was the difficulty of using it in extended lesions, because of the important tributaries and the necessity to resort to other complicated vascular "hybrid" procedures, the results of which were not superior, as a whole, to the ones of conventional open aortic replacement.

It is indeed interesting to observe that new techniques are easily adopted when there is no alternative. This was, for example, the case of coronary surgery in the late 60 s and early 70s. Conversely, if any other solution, even if not totally satisfactory, exists, changes and

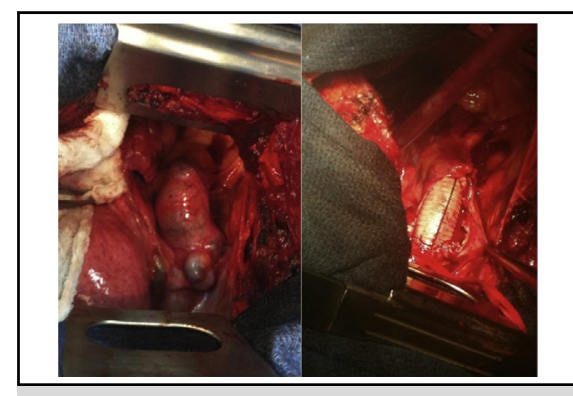

An impending rupture at the site of an aortic coarctation treated conventionally.

Central Message

This case dramatically illustrates the evolution of the treatment of acute thoracic aortic syndromes in the past 2 decades. Will then conventional open surgery totally disappear in the future?

See Article page e101.

implementation of new methods are generally slowly accepted. For instance, this was the case during the 70 s and early 80 s with the techniques of mitral repair, which are now considered a must.

In addition, during the same time, conventional aortic surgery made important progress. The use of a certain degree of hypothermia, the sequential cross-clamping of the aorta, the distal and visceral perfusion through the use of cardiopulmonary bypass or left ventricular assistance, the "collateral network concept," and cerebrospinal fluid drainage, were important adjuncts and key factors of improvement. Nevertheless, in addition to its immediate risks, one of the main reproaches made to conventional surgery was that it is highly aggressive physically and psychologically. Its morbidity, its trail of pains, either acute or chronic, of physical activity impairment, of negative aesthetic side effects, etc, constitute obviously one of the main causes of the reserve and criticism made about it.

So, the endovascular techniques are here and well established. And they can only improve. We can, indeed, observe the development of innovative attempts of using customized, fenestrated prostheses with collateral branches allowing the treatment of complex or poorly placed lesions. Of course, those experiences are scarce 
and still pertain to clinical research. One might wonder, by the way, why in a time when so many extraordinary techniques are developed and used in many industrial and scientific fields such as aviation, space, electronics, robotics, communication, etc, manufacturing those prostheses remains difficult and a quite protracted process and why their use remains rather anecdotal. Is it a matter of investment? But it is easy to imagine that those techniques, which are still in infancy, will improve and finally will find their rightful place.

It seems, thus, that conventional aortic surgery will see its sphere of action reduced before, perhaps, totally disappearing. Also it is likely that the treatment of the aortic diseases in the close future will be mainly performed by surgeons or therapists, trained in the techniques of the "cath lab," the interventional methods and, who knows, their robotic subsidiary.

\section{References}

1. Arakawa M, Yuri K, Takeuchi T, Okamura H. Thoracic endovascular aortic repair for ruptured pseudocoarctation. J Thorac Cardiovasc Surg. 2019;157:e101-3.

2. Dake MD, Miller DC, Semba CP, Mitchell RS, Walker PJ, Liddell RP. Transluminal placement of endovascular stent-grafts for the treatment of descending thoracic aortic aneurysms. N Engl J Med. 1994;331(26):1729-34. 